\title{
Universal coverage possible - with private sector support
}

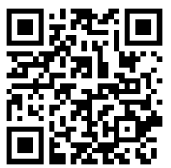

The private healthcare sector could, 'within a comparatively short time span', hugely relieve its overburdened public counterpart by nearly doubling its current medical scheme coverage of the population from $17 \%$ to $30 \%$. This private subsidy would increase the government's public sector per capita health spend by up to $19 \%$.

Healthcare actuary Barry Childs adds that for this much-needed pre-national health insurance (NHI) symbiosis to take place, government should complete its medical scheme regulatory reform and find ways to increase income cross-subsidies for schemes. Medical aid could be a lot more affordable if it could be made mandatory for everyone in formal employment above a specified income to belong to a medical scheme - and by bringing in a risk equalisation fund to create a level playing field between schemes, evening out the financial impact of different risk and demographic profiles. The medical aid schemes also urgently need to collaborate to reduce fraud and abuse, said Childs, and to 'buy smarter' by finding the most efficient providers and pathways of care, thus changing their mindset to 'active purchasing'.

'If we budget and think very carefully about how we run our medical schemes how to get the best bang for our buck - and put this all together, I estimate we could lower actual [medical aid] contributions by up to $30 \%$, he said. 'It is going to take some time to achieve universal coverage through the NHI plan, but we can provide much-needed relief to both the public and private sectors in just a few years if we could implement these reforms and initiatives ahead of time.' If only half of the potential savings were passed on to the existing market, the remainder could be used to significantly cross-subsidise the new tier market at similar benefit levels, which would significantly alleviate the load on the public sector.

Addressing the annual Hospital Association of South Africa (HASA's) annual conference at the Cape Town International Convention Centre on 28 October, Childs said that medical schemes have an unbalanced and incomplete regulatory framework. The foundations for social protection are in place through open enrollment, community rating and prescribed minimum benefits, but there

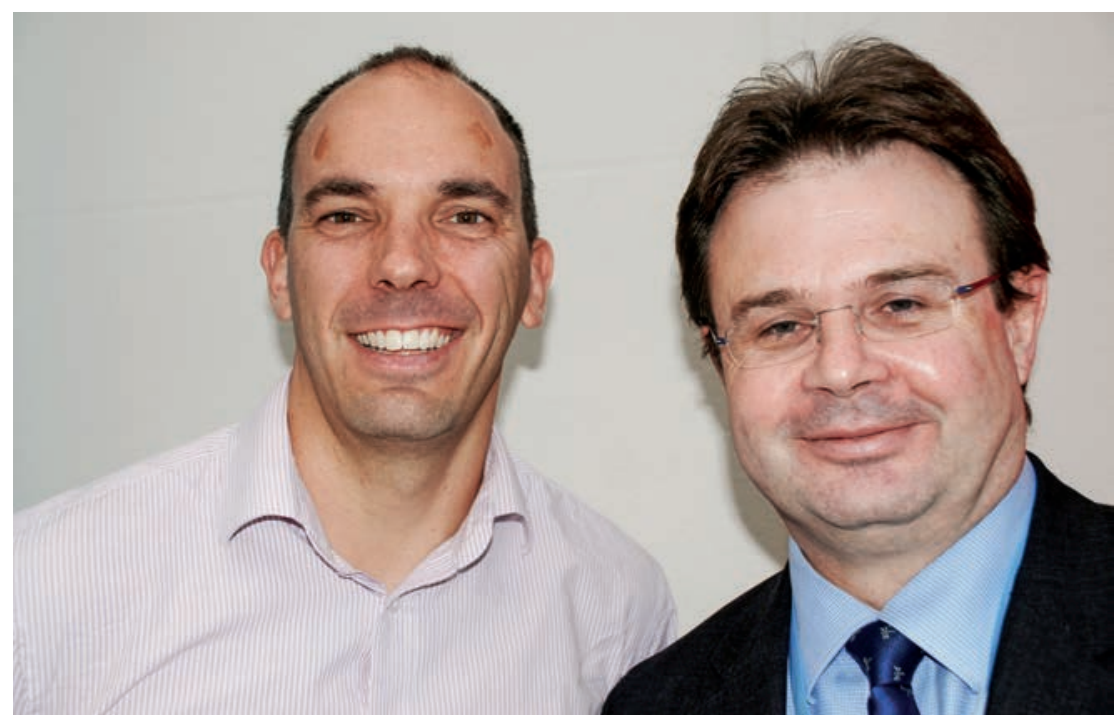

Healthcare actuary Barry Childs (left) and Stanlib chief economist Kevin Lings.

are none of the regulations required for the sustainability of the industry, such as mandatory membership, risk equalisation, risk-based capital and clarity on demarcation.

Childs called the current regulations, which prescribe huge risk solvency reserve levels for medical aid schemes, 'a significant waste of capital. 'Some schemes have massive cash reserves sitting in bank accounts and they can do almost nothing with that money, he said. He also took issue with the prescribed minimum benefits (PMBs) - a list of potentially catastrophic conditions which schemes are required to cover on all options and which play an important part of the social protection framework - describing them as a barrier to medical scheme entry for low-income families. He explained that just to cover the PMBs, the average cost of a medical scheme to a family was about R1 064 per month. Without greater income crosssubsidy, those costs are unaffordable for the majority of South Africans.

Childs said a lot more could be done to increase healthcare access and affordability. Medical schemes have been a 'regulatory orphan' since 2007, when the government turned its attention to NHI. Up until that point, government had been planning to make changes to the medical scheme industry - including a risk-equalisation fund and mandatory scheme membership for all employed people - that would have enabled lower-income workers to access private healthcare. However, the Medical Schemes Amendment Bill of 2008, which contained these reforms, was never processed by Parliament and lapsed.

The Council for Medical Schemes (CMS), under the stewardship of $\mathrm{Dr}$ Monwabisi Gantsho, has since drafted a new amendment bill, but this has yet to be submitted to Parliament or published for comment. Childs said it is highly unlikely that the new bill will contain all the measures needed to stabilise the medical schemes industry. Indeed, Gantsho is on record as saying that a risk equalisation fund is no longer part of the agenda. Such a fund would level the playing field between schemes that have lots of young and healthy members (and therefore lower healthcare costs) and those with more old and sick members. At present, schemes with a better risk profile can charge less and attract more young members. Childs also urged schemes and employers to work hard on preventive ('wellness') programmes to get people healthier, as this is one of the only solutions to the long-term trends in healthcare cost escalations.

\section{Healthcare divide mirrors 'two world' economy}

Echoing an earlier speaker on the costlowering theme, Stanlib's chief economist, Kevin Lings, Childs said that South Africa has the worst Gini co-efficient in the 
world. The Gini index measures the extent to which the distribution of income (or, in some cases, consumption expenditure) among individuals or households within an economy deviates from a perfectly equal distribution. In South Africa, the unequal distribution of healthcare reflects the rest of the economy. South Africans spent about R11 395 per capita on private healthcare annually, versus R2 835 per capita in the public healthcare sector. Childs said that $70 \%$ of South Africans live in households earning less than R7 500 per month, a statistic he called 'severely problematic'.

In his own presentation, Lings told the HASA audience that South Africans are a nation of 'shoppers - we don't make stuff or invest', adding that unsecured credit is growing at $42 \%$ per annum, with Capitec at one point last year processing 5000 loans an hour. Lings said that over the past five years government salaries and wages have doubled, quipping, 'We can't shop our way to success - our salaries and wages go to China ... it's not the way to grow an economy; we need a different mix.'

Lings said shopping alone accounted for 92\% of South Africa's economic growth. He felt that the top priority should be to invest in infrastructure and manufacturing to create more jobs and establish a massive middle class that can afford medical cover. 'First create jobs, then look at how you're going to distribute socio-economic services', he said. At present South Africa has a 'minute' tax base, in which 859000 of the 5.88 million taxpayers pay $53 \%$ of the total income tax bill. In order to expand access to medical schemes and hit the symbiotic 30\% coverage, the country needs a far bigger, stable middle class that is family-oriented, with technical skills and good opportunities.

Lings pointed out that South Africa consists of 'two worlds': one is skilled with a higher income, can afford private services, and has formal employment and access to technology; the other has high unemployment, low income, poor education, lack of access to services, low savings and relative youth. 'We need the two worlds to intersect substantially - the differences are too stark', he said. The irony is that South Africa shifts between Number 1 and Number 3 in the Global Competitiveness Ranking, is Number 3 in the soundness of its well-managed and well-regulated banks and is Number 2 in global financial transparency. "We stand head and shoulders above most. Two years ago we were ahead of New Zealand [in the Global Transparency ranking]. Now they are Number 1,' he said.

However, Lings stressed, 'that does not mean government spends the money wisely. It means it allocates it wisely and transparently. It doesn't mean we don't squander the money!'

\section{SA can afford a well-} managed NHI - Lings

Government debt as a percentage of South Africa's gross domestic product (GDP) stands at $40 \%$, quite low on a world scale. 'We can therefore consider national health insurance', said Lings. 'Greece can't, Japan sits at $200 \%$ of GDP and Italy is the next worst. We need to use our advantage wisely.'

Currently, debt servicing costs stand at well below $10 \%$, down from double that figure when the ANC inherited a badly managed fiscal regime. Interest rates have plummeted from $14.6 \%$ to $5.2 \%$ and remain low (the lowest since 1974), meaning that the cost of starting a business or buying a home is reasonable. The FIFA World Cup, while not a huge money spinner at the time, has led to more people with more money making this country a tourist destination, with record tourism earnings currently, and many visitors from Africa itself. Foreign exchange reserves held by the Reserve Bank stood at about R50 billion, up from about R3 billion in 1997.

\section{'You can't survive on a social} grant', said Lings. 'We'd like to increase it, but we can't afford to pay a living income when more people receive a social grant than those who work!'

Lings said that these facts seldom make the newspapers and other media. What did hit the headlines was South Africa being ranked nearly last (146th) in the quality of our education system, with only half a million children writing matric annually (about half the desired number). 'What happened to these children, where are these kids?' he asked. They have dropped out of school, yet the government message is that South Africa has a $73 \%$ pass rate. The current unemployment rate of people younger than 24 years is $51 \%$, while monthly social grants have risen from about 3 million to 16 million - more than the number of people working.
'You can't survive on a social grant,' said Lings. 'We'd like to increase it, but we can't afford to pay a living income when more people receive a social grant than those who work! If we don't increase employment, these numbers will just get bigger.'

He described South Africa as the very opposite of China: 'They achieved spectacular growth by building a lot of stuff. Their fixed investment activity sits at almost $50 \%$ of GDP. They've overbuilt - they have to slow down on building and pick up on shopping - we must do the opposite. [Finance Minister] Pravin Gordhan knows this. He's saying we [our government] can't spend as much money on salaries and wages - we need to spend more on public sector infrastructure.' Gordhan wants to raise R827 billion over the next three years, which Lings said 'won't change the country without anything else happening', but would take us closer to the $25 \%$ of spending on fixed investments as a percentage of GDP, which he said needs to be maintained for a decade.

\section{Corporate 'cash huggers' bidling their time}

Lings said part of the answer lay in unlocking huge corporate sector capital, currently sitting idle in banks - what he described as 'a massive cash pile, the highest ever recorded', and estimated at over R550 billion currently. The reason these corporates are 'hugging their cash, waiting', is that they have lost confidence. 'Would you want to invest in a business without electricity or inadequate port capacity?' he asked.

Lings said the first goal is to unlock the infrastructural bottlenecks (e.g. road, rail, electricity) to create business opportunities. As balance sheets begin to work, employment will increase. 'Name any social or economic problem in South Africa, anything. And I promise you every one gets less, the more you employ. Every job you add systematically diminishes all the problems at the same time. Take the jobless 24-year-old guy in Diepsloot. If you try and change his circumstances before he has a job, you wreck the financial position of the government, because the tax base is far too small,' he said.

\section{Chris Bateman}

chrisb@hmpg.co.za

S Afr Med J 2014;104(1):8-9. DOI:10.7196/SAMJ.7797 